\title{
Biospecimen Science of Blood for cfDNA Genetic Analyses
}

\author{
Wim Ammerlaan $^{1} \cdot$ Fay Betsou ${ }^{1}$
}

Published online: 16 April 2019

(C) The Author(s) 2019

\begin{abstract}
Purpose of Review cfDNA is increasingly used for biomonitoring oncological diseases or pregnancy status by different genetic analyses. Uncontrolled pre-analytical variability impacts the quality and quantity and subsequently undermines the utility of this analyte. In this review, we summarize critical pre-analytical factors to be addressed, to avoid irreproducible results.

Recent Findings cfDNA quantity and quality can be impacted by the in vivo condition of the donor and the ex vivo biospecimen handling prior to the downstream analysis. In vivo, physical and psychosocial stress, circadian rhythmicity, and age appear to be critical. Ex vivo, the blood collection tubes, pre-centrifugation storage temperature and time, and cfDNA extraction kits are important.

Summary To address these critical pre-analytical viabilities, in-process quality control material should be applied. Plasma is preferred to serum, as are blood collection tubes with stabilizers. Finally, the donor status and sample processing should be standardized and documented.
\end{abstract}

Keywords cfDNA $\cdot$ Human blood $\cdot$ Pre-analytics $\cdot$ Genetic analysis $\cdot$ Quality control

\section{Fitness-for-Purpose of cfDNA for Genetic Analyses}

Described for the first time in 1948 [1], cfDNA can be used as a substrate for genetic analyses by next-generation sequencing (NGS), digital PCR or BEAMing digital PCR, and methylation specific PCR. Diagnostic non-invasive prenatal testing (NIPT) routinely uses maternal and fetal cfDNA and several FDAapproved and CE-marked kits [2,3]. Recently, sequencing of cfDNA in maternal plasma has even been suggested as a tool for paternity testing [4]. Analysis of cfDNA for prognosis of cancer recurrence or metastasis, based on monitoring and increase of cfDNA concentrations, as well as for prediction of success of cancer therapies, and adaptation of targeted therapies, based on appearance of new variants, is likely to be implemented

This article is part of the Topical Collection on Biospecimens Science and Evidence-Based Standards for Precision Medicine

Wim Ammerlaan

Wim.Ammerlaan@ibbl.lu

Fay Betsou

Fay.Betsou@ibbl.lu

1 IBBL, 1 rue Louis Rech, L-3555 Dudelange, Luxembourg in clinical diagnostics [5]. An FDA-approved cfDNA-based diagnostic test is the Roche Cobas plasma EGFR mutation test V2 to guide treatment decisions in lung cancer patients. Emerging applications in oncology have been reviewed by Komatsubara and Sacher [6] and cfDNA is already being used in clinical trials and healthcare, e.g., by Guardant Health in the USA, based on enrichment by hybrid capture [7] or with Biocartis real-time PCR assays (https://www.genomeweb.com/pcr/biocartis-gets-cemarking-two-colorectal-cancer-liquid-biopsy-tests\#. WvgVaGcR1vA). The cfDNA methylation is also being explored as a biomarker in colorectal cancer [8] and NIPT [9].

For NGS-targeted oncogenic mutation analyses on a panel of around 50 genes, Illumina technologies require a minimum DNA input amount of around $150 \mathrm{ng}$, which is too high for cfDNA. However, enrichment by hybrid capture (Agilent Technologies) allows library preparation and Illumina sequencing from 5 to $30 \mathrm{ng}$ of extracted cfDNA [10], while alternative library preparation technologies have been developed by Life Technologies, with minimum DNA input amount of less than $10 \mathrm{ng}$ [11]. The efficiency of ddPCR in terms of minimum DNA input amount/sensitivity is very high, exhibiting detection of mutation prevalence between 0.005 and $0.01 \%$, with a sensitivity of 5 to 50 mutant copies in a background of 10,000 wild-type copies, and with an input of 10-30 ng DNA per reaction [12]. 
In disease areas other than cancer, such as NAFL NASH, the use of cfDNA as a diagnostic or prognostic biomarker is at the exploratory research stage, for example in the clinical evolution of NAFL disease [13]. The measurement of cfDNA has also been proposed as a diagnostic biomarker in myocardial infarction [14], a prognostic biomarker in monitoring of transplant patients [15], and as a prognostic biomarker in trauma and intensive care unit patients [16].

The mechanisms of release of cfDNA in the circulation are not completely elucidated. While cell necrosis and apoptosis have long been considered as the main mechanisms, active release of DNA molecules from living cells is also possible [17, 18]. Active and rapid release of DNA in the circulation may take place through mechanisms, such as the release of exosomes [19]. Therefore, although this is the general consensus, it is not absolutely certain that only mononucleosomal size DNA fragments of around $180 \mathrm{bp}$ are of clinical interest. Higher MW fragments may as well contain clinically important genetic information, if they originate from the tissue of interest.

As for any other biomarkers, fitness-for-purpose of the specimens being used for cfDNA genetic analysis is necessary for the accuracy of the results $[20 \bullet, 21 \bullet \cdot$. Uncontrolled and undocumented pre-analytics may introduce catastrophic bias, invalidate clinical analytical results, or lead to irreproducible research publications.

\section{Critical In Vivo Pre-analytical Factors}

Many types of stress induce an increase in the levels of cfDNA. Chronic stress and inflammation are linked to apoptosis- and necrosis-mediated long-term release of DNA, while acute stress, such as anaerobic exercise, is linked to rapid DNA release, through mechanisms that have not yet been completely elucidated. Chronic endurance training leads to constant release of DNA and persistent increase of cfDNA levels, due to both acute oxidative stress and inflammatory processes taking place during damage and repair of muscle cells [22]. Not only physical stress, but also psychosocial stress has been shown to induce an increase in cfDNA levels and an alteration of cfDNA methylation profile [23]. Acute viral infections, such as HIV, hepatitis B, or Epstein Barr Virus infection, may induce an increase in the cfDNA levels due to the presence of viral DNA [24].

In an oncological context, tumor variables, such as disease stage, tumor volume, tumor grade, type of tumor (primary or metastatic), but also treatment status, all have an influence on the amounts of cfDNA. This association is at the basis of the use of cfDNA in clinical diagnostics [5-7].

Circadian rhythmicity might also affect the levels of cfDNA as has been suggested in a study where most of the subjects presented higher cfDNA levels at mid-day [25]. The same circadian rhythmicity, with higher cfDNA levels at mid- day, was observed in colorectal cancer patients of stages I-III, but not stage IV [26]. Environmental exposures, such as exposure to pesticides, may influence the levels of cfDNA; these levels were found to be higher in males than in females [27]. Finally, age is a significant covariable when one studies relative cfDNA amounts at specific genomic locations, such as transcription start and termination sites, or cfDNA-associated methylation signals, corresponding to different tissue types [28] (Fig. 1).

\section{Critical Ex Vivo Pre-analytical Factors}

There are two main challenges when processing serum or plasma to obtain cfDNA for downstream analysis. The first is the low concentration, of around 1000 genome equivalents per milliliter of blood [29], (few ng per ml of plasma in healthy individuals), introducing the need for highest yield to ensure best sensitivity of the downstream analysis. The second is the possible "contamination" of cfDNA by bigger size genomic DNA fragments, originating from white blood cells (WBC) and introducing the need for WBC stabilization to ensure best specificity of the downstream analysis.

The blood collection tube type is the first critical preanalytical factor.

The question of serum versus plasma has been debated. Extraction of circulating DNA consistently gives fiveeightfold higher yields in serum than in plasma [30, 31•] Fig. 2. Moreover, Warton et al. have shown [31•] that when spiking blood, collected in serum blood collection tube (BCT), with high MW DNA, this spiked DNA is not recovered or detected electrophoretically in the extracted serum cfDNA. On the contrary, it is effectively detected in the plasma cfDNA extract. It appears that high MW DNA is trapped in the clot during the coagulation process.

Another study having evaluated serum versus plasma is the one by Parpart-Li et al. who found significantly more total genome equivalents (GEs), but significantly lower mutant allele fractions in serum than in EDTA plasma from cancer patients. The fragment sizes in the cfDNA fraction extracted from serum ranged from 150 to $2000 \mathrm{bp}$ while the samples from plasma showed the single typical peak at around 150 [32•]. Release of cellular DNA therefore seems to be taking place during the blood clotting process from lysing cells, and this explains the higher yield of circulating DNA obtained from serum. As a conclusion, serum is a more unstable and difficult-to-control fluid, due to the coagulation process and is not recommended as starting material for commercial cfDNA analysis kits.

Therefore, anticoagulated blood is the preferred option for any cfDNA-based genetic analysis assay. EDTA has been suggested as a better anticoagulant than citrate or heparin [33], and currently available diagnostic kits require EDTA plasma as primary material. 
Fig. 1 Summary of in vivo and ex vivo critical pre-analytical factors for cfDNA analyses
The next question is whether the anticoagulated blood should be stabilized or not and with what type of stabilizer. Non-stabilized blood is blood collected in an anticoagulant, such as EDTA, citrate, or heparin, while stabilized blood is collected in tubes with a chemical stabilizer, such as

\section{ex-vivo}

\section{Circadian rythm}

Age

Viral Infections stress

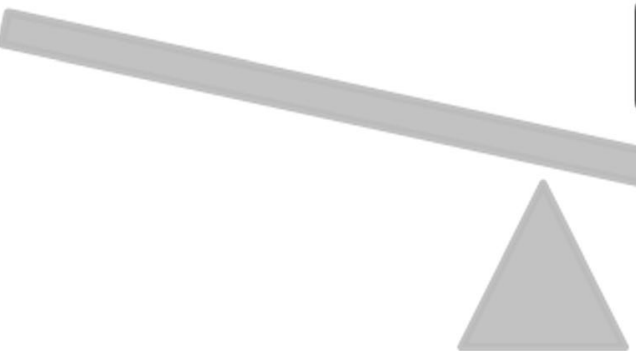

Blood collection tube and stabiliser
cfDNA storage

temperature

\section{Extraction kit}

Precentrifugation delay

and storage temperature
Fig. 2 Representative examples of cfDNA yield ( $\mathrm{ng} / \mathrm{ml}$ plasma), extracted by QIAamp cfDNA extraction method, from different healthy donors
PAXgene, Streck, and PAXgene ccfDNA tubes. The standard PAXgene tubes that have been used for years for blood cell nucleic acid-based analyses are inadequate for cfDNA isolation because of extensive cell lysis [34]. Cell lysis also occurs in EDTA tubes, upon prolonged incubation of the blood,

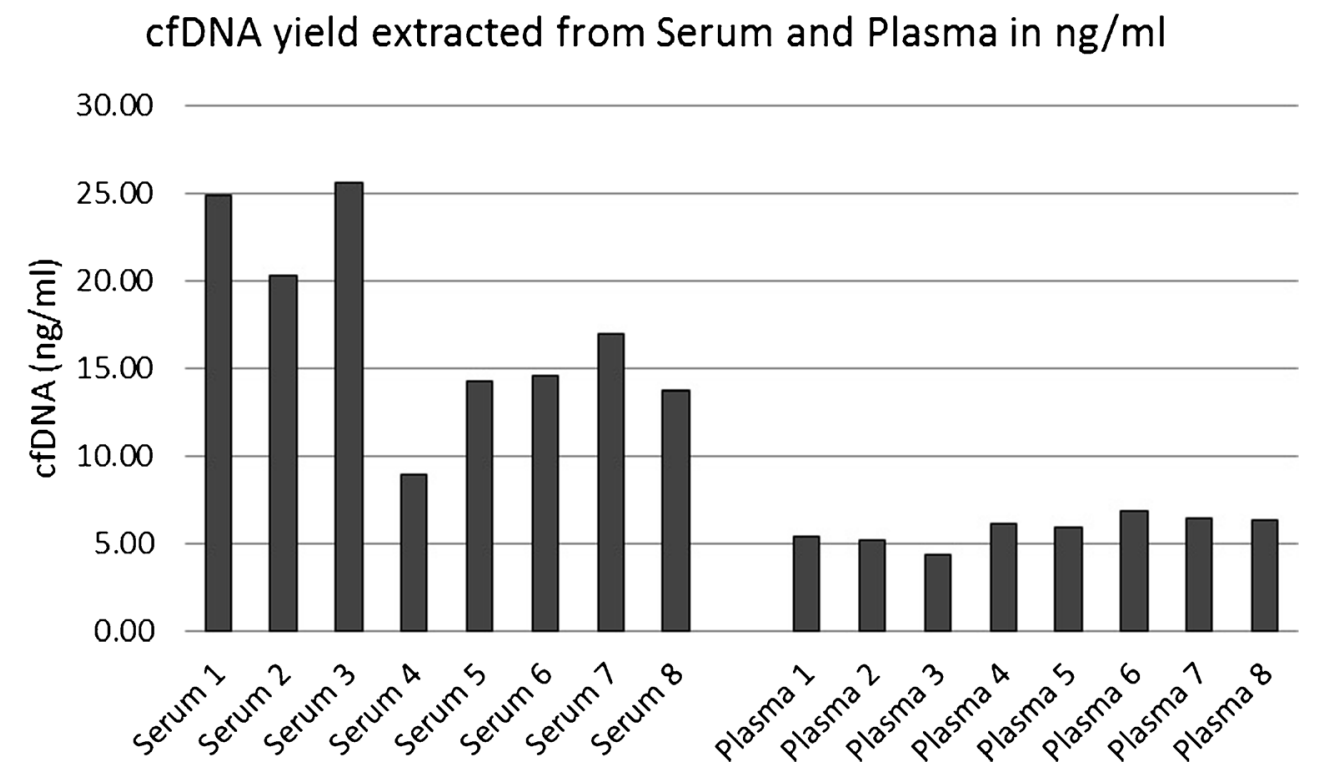


especially at room temperature (RT). Following such WBC lysis, cellular genomic DNA fragments as well as DNases are released. These DNases may degrade the cfDNA, even though it has been shown that EDTA inhibits to a certain degree endogenous DNases [35].

Blood cell lysis is avoided by stabilization solutions, used in Streck, CellSave, Roche, Norgen Biotek, or PAXgene ccfDNA tubes [36-38]. Yields and performance of cfDNA are comparable from Streck BCT, Roche, and PAXgene ccfDNA tubes, with reliable qPCR detection of target mutations, when the spiked DNA quantity was as low as $0.5 \mathrm{ng}$, and even after 7-day RT tube storage [39•](also Ammerlaan, $I B B L$, unpublished author experience). Recently, an abstract from Qiagen indicated that Streck tubes may contain formaldehyde which can induce DNA deaminations and introduce bias in cfDNA methylation analyses [40]. Furthermore, PAXgene ccfDNA tubes allow unbiased quantification of methylated sequences to be performed and are therefore fitfor-purpose for downstream cfDNA methylation analyses [41]. The concern that the Streck tube preservative might introduce DNA sequence modifications was recently dismissed by Risberg et al. who showed that there is no difference in background error rate between cfDNA extracted from Streck BCT and from paired EDTA samples and analyzed by Tagged Amplicon deep sequencing (Tam-Seq) [42••].

The CellSave tubes are tubes containing a preservative, specific for the stabilization of circulating tumor cells (CTCs). These tubes were shown to be fit-for-purpose for the isolation of cfDNA in the scope of copy number variation analysis by NGS [43].

The time and temperature between blood collection and plasma isolation is the second most important pre-analytical factor. Concerning the maximum allowable time between blood collection and processing by centrifugation for plasma separation, all biospecimen research studies indicate that EDTA blood should be processed in the 3-6 h following collection, if stored at room temperature. If EDTA blood is stored at $4{ }^{\circ} \mathrm{C}$, the delay can safely be extended to $8 \mathrm{~h}$ when using the QIAamp MinElute Virus Spin Kit [31•] or to $24 \mathrm{~h}$ [32•, 44-49]. For blood collection tubes with stabilizers, stability claims of the manufacturers have generally been confirmed (see above references): 7 days at RT for Streck $\mathrm{BCT}$ and PAXgene ccfDNA tubes. The stability of the cfDNA collection tube from Roche Diagnostics $\mathrm{GmBH}$ seems to be lower [50*].

Concerning the centrifugation conditions, the consensus is for double spun plasma with a second high-speed centrifugation at $16000 \mathrm{~g}$ before cfDNA extraction.

The cfDNA extraction kit is the third most important pre-analytical factor. The most commonly used extraction kits or methods are listed in Table $1[49,51]$.

Different kits may provide different yields of cfDNA. A comparative study between 11 different kits and methods showed highest cfDNA yields with the Norgen Kits [52].
Different kits may produce cfDNA of different size ranges, depending on the binding capacity of the beads or membranes used during the extraction process. The processing laboratory should validate the MW range of DNA molecules that are effectively extracted. As of today, it is not clear if DNA molecules of higher MW are of clinical interest or not. It cannot be excluded that tumor cells dying of necrosis release high MW DNA that may be recovered in the cfDNA eluate with some, but not with other extraction kits. A recent comparison between six different column-based or magnetic bead-based kits used DNA spikes of different sizes (50-808 bp). This study showed that some kits, such as the QIAamp Circulating Nucleic Acid Kit and the Norgen Plasma/Serum Cell-Free Circulating DNA Purification Kit, provide very good recovery of DNA fragments of all sizes, while the MagMAX Cell-Free DNA Isolation Kit does not allow recovery of the lower size (50 bp) DNA fragments, and the Bioo Next-Prep-Mag cfDNA Isolation Kit allows good recovery of DNA fragments, only in the range of $75-300 \mathrm{bp}[53 \bullet \cdot]$.

For downstream cfDNA methylation analyses, fitness-forpurpose of the cfDNA has been shown and a modified MethylMiner (Invitrogen) protocol for isolation of the methylated cfDNA sequences has been described [31•]. If bisulfite conversion is used, the Bisulfite Conversion Kit is another critical pre-analytical factor. Although there are many Bisulfite Conversion Kits, the one that is the most fit-for-purpose for bisulfite conversion of cfDNA in plasma is the InnuCONVERT Bisulfite Body Fluids Kit (Analytik Jena AG), which works with up to 3-ml volumes of input samples [54]. If bisulfite conversion is performed on isolated cfDNA, the Epitect (Qiagen) Kit can be used with the "Small Amounts of Fragmented DNA" protocol [54]. Finally, a single tube extraction and processing method, named "methylation on beads" has been described, which allows for cfDNA extraction and bisulfite conversion from up to $2 \mathrm{ml}$ of plasma and ensures high recovery and analytical sensitivity of methylation analysis [55].

Once cfDNA has been extracted, its long-term stability at $-80{ }^{\circ} \mathrm{C}$ may not be guaranteed, and therefore, long-term storage in liquid nitrogen (LN) would be a safer decision [56]. Protocols for whole genome amplification (WGA) from plasma are commercialized (Sigma-modified WGA2 or Sigma-modified WGA4 protocols, https://www. sigmaaldrich.com/technical-documents/protocols/biology/ whole-genome-amplification-serum-or-plasma.html); however, no independent validation has been published. cfDNA fragments of around $150 \mathrm{bp}$ are too short for WGA (Trouet, IBBL, unpublished author experience).

A first set of evidence-based guidelines for processing specimens for cfDNA analyses was published by El Messaoudi et al. [57]. More evidence-based procedures and recommendations are being prepared by the European consortium CANCER-ID (https://www.cancer-id.eu/), in the context of the Innovative Medicines Initiative (IMI). The European 
Table 1 List of most commonly used cfDNA extraction kits, the companies that produce them, and the principle of the methods used

\begin{tabular}{|c|c|c|}
\hline cfDNA isolation kit name & Company & Method \\
\hline QIAamp Circulating Nucleic Acid Kit D2 & QIAgen & $\begin{array}{l}\text { Silica membrane } \\
\text { column }\end{array}$ \\
\hline QIAamp DNA Blood Mini Kit & QIAgen & $\begin{array}{l}\text { Silica membrane } \\
\text { column }\end{array}$ \\
\hline QIAsymphony DSP Circulating DNA Kit & QIAgen & Magnetic beads \\
\hline QIAamp MinElute ccfDNA Kit & QIAgen & $\begin{array}{l}\text { Silica membrane } \\
\text { column }\end{array}$ \\
\hline MagMax Cell-Free DNA Isolation Kit & $\begin{array}{l}\text { Applied } \\
\text { Biosystems }\end{array}$ & Magnetic beads \\
\hline Maxwell RSC ccDNA Plasma Kit & Promega & Magnetic beads \\
\hline Chemagic Next Prep cfDNA (Perkin Elmer) & Perkin Elmer & Magnetic beads \\
\hline NextPrep-Mag cfDNA Isolation Kit & Perkin Elmer & Magnetic beads \\
\hline Nucleospin Plasma XS Kit & Macherey-Nagel & $\begin{array}{l}\text { Silica membrane } \\
\text { column }\end{array}$ \\
\hline FitAmp Plasma/Serum DNA Isolation Kit & Epigentek & $\begin{array}{l}\text { Silica membrane } \\
\text { column }\end{array}$ \\
\hline GenElute Blood Genomic DNA kit & Sigma & $\begin{array}{l}\text { Silica membrane } \\
\text { column }\end{array}$ \\
\hline $\begin{array}{l}\text { Norgen Plasma/Serum Circulating DNA Purification Kit (slurry } \\
\text { format) }\end{array}$ & Norgen & $\begin{array}{l}\text { Silica membrane } \\
\text { column }\end{array}$ \\
\hline $\begin{array}{l}\text { Norgen Plasma/Serum Cell-Free Circulating DNA Purification } \\
\text { Kit }\end{array}$ & Norgen & $\begin{array}{l}\text { Silica membrane } \\
\text { column }\end{array}$ \\
\hline Quick-cfDNA/cfRNA Serum and Plasma Kit & Zymo Research & $\begin{array}{l}\text { Silica membrane } \\
\text { column }\end{array}$ \\
\hline Phenol-chloroform-based method & Hufnagl 2013 [51] & $\begin{array}{l}\text { Laboratory } \\
\text { developed }\end{array}$ \\
\hline Triton/Heat/Phenol-based method & Xue 2009 [49] & $\begin{array}{l}\text { Laboratory } \\
\text { developed }\end{array}$ \\
\hline
\end{tabular}

program SPIDIA (http://www.spidia.eu/) has also developed a CEN Technical Specification standard for the pre-analytical phase of ccfDNA [58].

\section{Quality Control Materials}

Few in-process quality control materials exist that can be used for the validation of the cfDNA extraction methods. Horizon commercializes cfDNA Reference Standards Reference Standards for method validation purposes (research use only). These materials are provided as mechanically sheared, fragmented DNA (average size $160 \mathrm{bp}$ ) from engineered human cell lines and contain variants at allelic frequencies down to $0.1 \%$ [59], https://www.horizondiscovery.com/media/resources/ Application\%20Notes/reference-standards/independent-dPCRstudy-of-horizon-cfdna-reference-standards.pdf.

Devonshire et al. have developed and validated spike materials that allow users to measure cfDNA extraction efficiency, fragment size bias, and yield [60••]. These materials are based on a linearized and digested plasmid, containing the Arabidopsis thaliana alcohol dehydrogenase gene (ADH), and fragments have sizes of $189 \mathrm{bp}$ and roughly $3 \mathrm{~kb}$.
A homemade reference material that has been described, for the analytical validation of a cfDNA NGS assay, is based on overlapping extension PCR for site-directed mutagenesis to obtain fragments of 537 to $2030 \mathrm{bp}$, containing specific mutation sequences [4].

The validation of the cfDNA extraction method is based on measurement of (i) the concentration and yield of the cfDNA extracted from the in-process QC material, either by high sensitivity spectrofluorometry or by qPCR or dPCR and (ii) the integrity of the cfDNA extracted from the in-process QC material, either by microfluidic electrophoresis or by qPCR on amplicons of different lengths [61].

\section{Conclusion}

The context of use of cfDNA has extended from the NIPT to oncological indications, while research and development on cfDNA is ongoing in other disease areas. Standardization of the cfDNA pre-analytical phase is key for the accuracy of genetic analyses and the reproducibility of research results. The commercialization of blood collection tubes with stabilizers precluding blood cell lysis has increased the robustness and specificity of 
cfDNA testing. Different in vivo and ex vivo critical preanalytical factors may affect the yield, the size range, and the integrity of the recovered cfDNA, leading to a decrease in sensitivity and/or specificity of cfDNA-based genetic analyses. These factors should be acknowledged, documented, and taken into account in cfDNA-based research data analyses.

Acknowledgments We are grateful to Johanna Trouet for excellent work on some cfDNA pre-analytical aspects.

\section{Compliance with Ethics Guidelines}

-Conflict of Interest The authors declare that they have no conflict of interest.

-Human and Animal Rights and Informed Consent This article does not contain any studies with human or animal subjects performed by any of the authors.

Open Access This article is distributed under the terms of the Creative Commons Attribution 4.0 International License (http:// creativecommons.org/licenses/by/4.0/), which permits unrestricted use, distribution, and reproduction in any medium, provided you give appropriate credit to the original author(s) and the source, provide a link to the Creative Commons license, and indicate if changes were made.

\section{References}

1. Mandel P, Metais P. Comptes rendus des seances de la Societe de biologie et de ses filiales. Sci Res. 1948;142:241-3.

2. Skrzypek H, Hui L. Noninvasive prenatal testing for fetal aneuploidy and single gene disorders. Best Pract Res Clin Obstet Gynaecol. 2017;42:26-38.

3. Liu L, Li K, Fu X, Chung C, Zhang K. A forward look at noninvasive prenatal testing. Trends Mol Med. 2016;22(11):958-68.

4. Yang X, Chu Y, Zhang R, Han Y, Zhang L, Fu Y, et al. Technical validation of a next-generation sequencing assay for detecting clinically relevant levels of breast cancer-related single-nucleotide variants and copy number variants using simulated cell-free DNA. J Mol Diagn. 2017.

5. Cree IA, Uttley L, Woods HB, Kikuchi H, Reiman A, Harnan S, et al. The evidence base for circulating tumour DNA blood-based biomarkers for the early detection of cancer: a systematic mapping review. BMC Cancer. 2017;17(1):697.

6. Komatsubara KM. Circulating tumor DNA as a liquid biopsy: current clinical applications and future directions: Page 3 of 3 . Oncology. 2017;31(8).

7. Hu Y, Alden RS, Odegaard JI, Fairclough SR, Chen R, Heng J, et al. Discrimination of germline EGFR T790M mutations in plasma cell-free DNA allows study of prevalence across 31,414 cancer patients. Clin Cancer Res. 2017;23:7351-9.

8. Ørntoft M-BW. Review of blood-based colorectal cancer screening: how far are circulating cell-free DNA methylation markers from clinical implementation? Clinical Colorectal Cancer. 2018.

9. Lim JH, Kim KS, Kim HJ, Lee BY, Park SY, Ahn HK, et al. Noninvasive detection of fetal trisomy 21 using fetal epigenetic biomarkers with a high CpG density. Clin Chem Lab Med. 2014;52(5):641-7.

10. Odegaard JI, Vincent JJ, Mortimer S, Vowles JV, Ulrich BC, Banks $\mathrm{KC}$ et al. Validation of a plasma-based comprehensive cancer genotyping assay utilizing orthogonal tissue-and plasma-based methodologies. Clin Cancer Res. 2018:clincanres. 3831.2017.

11. Weerts MJ, van Marion R, Helmijr JC, Beaufort CM, Krol NM, Trapman-Jansen AM, et al. Somatic tumor mutations detected by targeted next generation sequencing in minute amounts of serumderived cell-free DNA. Sci Rep. 2017;7:2136.

12. Sacher AG, Paweletz C, Dahlberg SE, Alden RS, O'Connell A, Feeney N, et al. Prospective validation of rapid plasma genotyping as a sensitive and specific tool for guiding lung cancer care. JAMA Oncol. 2016;2(8):1014-22.

13. Karlas T, Weise L, Kuhn S, Krenzien F, Mehdorn M, Petroff D, et al. Correlation of cell-free DNA plasma concentration with severity of non-alcoholic fatty liver disease. J Transl Med. 2017;15(1):106.

14. Chang CP-Y, Chia R-H, Wu T-L, Tsao K-C, Sun C-F, Wu JT. Elevated cell-free serum DNA detected in patients with myocardial infarction. Clin Chim Acta. 2003;327(1-2):95-101.

15. Grskovic M, Hiller DJ, Eubank LA, Sninsky JJ, Christopherson C, Collins JP, et al. Validation of a clinical-grade assay to measure donor-derived cell-free DNA in solid organ transplant recipients. J Mol Diagn. 2016;18(6):890-902.

16. Saukkonen K, Lakkisto P, Varpula M, Varpula T, Voipio-Pulkki L$\mathrm{M}$, Pettilä V, et al. Association of cell-free plasma DNA with hospital mortality and organ dysfunction in intensive care unit patients. Intensive Care Med. 2007;33(9):1624-7.

17. Stroun M, Lyautey J, Lederrey C, Olson-Sand A, Anker P. About the possible origin and mechanism of circulating DNA: apoptosis and active DNA release. Clin Chim Acta. 2001;313(1-2):139-42.

18. Aucamp J, Bronkhorst AJ, Badenhorst CP, Pretorius PJ. The diverse origins of circulating cell-free DNA in the human body: a critical re-evaluation of the literature. Biol Rev Camb Philos Soc. 2018;93(3):1649-83.

19. Record M, Subra C, Silvente-Poirot S, Poirot M. Exosomes as intercellular signalosomes and pharmacological effectors. Biochem Pharmacol. 2011;81(10):1171-82.

20. Bronkhorst AJ, Aucamp J, Pretorius PJ. Cell-free DNA: preanalytical variables. Clin Chim Acta. 2015;450:243-53. This is a general review of cfDNA preanalytical variables.

21.• Barták BK, Kalmár A, Galamb O, Wichmann B, Nagy ZB, Tulassay $Z$, et al. Blood collection and cell-free DNA isolation methods influence the sensitivity of liquid biopsy analysis for colorectal cancer detection. Pathol Oncol Res. 2018:1-9. This is a review of cfDNAvariables in the scope of a clinical diagnostic test.

22. Breitbach S, Tug S, Simon P. Circulating cell-free DNA. Sports Med. 2012;42(7):565-86

23. Hummel E, Hessas E, Müller S, Beiter T, Fisch M, Eibl A, et al. Cell-free DNA release under psychosocial and physical stress conditions. Transl Psychiatry. 2018;8(1):236.

24. Kanegane H, Wakiguchi H, Kanegane C, Kurashige T, Miyawaki T, Tosato G. Increased cell-free viral DNA in fatal cases of chronic active Epstein-Barr virus infection. Clin Infect Dis. 1999;28(4):906-9.

25. Korabecna M, Horinek A, Bila N, Opatrna S. Circadian rhythmicity and clearance of cell-free DNA in human plasma. Circulating Nucleic Acids in Plasma and Serum. Springer; 2010. p. 195-198.

26. Tóth K, Patai ÁV, Kalmár A, Barták BK, Nagy ZB, Galamb O, et al. Circadian rhythm of methylated Septin 9, cell-free DNA amount and tumor markers in colorectal cancer patients. Pathol Oncol Res. 2017;23(3):699-706.

27. Çayir A, Coskun M, Coskun M, Cobanoglu H. DNA damage and circulating cell free DNA in greenhouse workers exposed to pesticides. Environ Mol Mutagen. 2018;59(2):161-9.

28. Teo YV, Capri M, Morsiani C, Pizza G, Faria AMC, Franceschi C, et al. Cell-free DNA as a biomarker of aging. Aging Cell. 2018:e12890.

29. Chiu RW, Poon LL, Lau TK, Leung TN, Wong EM, Lo YD. Effects of blood-processing protocols on fetal and total DNA quantification in maternal plasma. Clin Chem. 2001;47(9):1607-13. 
30. Ammerlaan W, Trezzi J-P, Lescuyer P, Mathay C, Hiller K, Betsou F. Method validation for preparing serum and plasma samples from human blood for downstream proteomic, metabolomic, and circulating nucleic acid-based applications. Biopreservation and Biobanking. 2014;12(4):269-80.

31. Warton K, Lin V, Navin T, Armstrong NJ, Kaplan W, Ying K, et al. Methylation-capture and next-generation sequencing of free circulating DNA from human plasma. BMC Genomics. 2014;15(1):476. This is a study on cfDNA and methylation analyses.

32. Parpart-Li S, Bartlett B, Popoli M, Adleff V, Tucker L, Steinberg R, et al. The effect of preservative and temperature on the analysis of circulating tumor DNA. Clin Cancer Res. 2017;23(10):2471-7. This is a study showing how the molecular quality attributes of cfDNA are modified by preanalytical variables.

33. Lam NY, Rainer TH, Chiu RW, Lo YD. EDTA is a better anticoagulant than heparin or citrate for delayed blood processing for plasma DNA analysis. Clin Chem. 2004;50(1):256-7.

34. Toro PV, Erlanger B, Beaver JA, Cochran RL, VanDenBerg DA, Yakim E, et al. Comparison of cell stabilizing blood collection tubes for circulating plasma tumor DNA. Clin Biochem. 2015;48(15):993-8.

35. Barra GB, Santa Rita TH, de Almeida VJ, Chianca CF, Nery LFA, Costa SSS. EDTA-mediated inhibition of DNases protects circulating cell-free DNA from ex vivo degradation in blood samples. Clin Biochem. 2015;48(15):976-81.

36. Kang Q, Henry NL, Paoletti C, Jiang H, Vats P, Chinnaiyan AM, et al. Comparative analysis of circulating tumor DNA stability in K3EDTA, Streck, and CellSave blood collection tubes. Clin Biochem. 2016;49(18):1354-60.

37. Sherwood JL, Corcoran C, Brown H, Sharpe AD, Musilova M, Kohlmann A. Optimised pre-analytical methods improve KRAS mutation detection in circulating tumour DNA (ctDNA) from patients with non-small cell lung cancer (NSCLC). PLoS One. 2016;11(2):e0150197.

38. Dessel LF, Beije N, Helmijr JC, Vitale SR, Kraan J, Look MP, et al. Application of circulating tumor DNA in prospective clinical oncology trials-standardization of preanalytical conditions. Mol Oncol. 2017;11(3):295-304.

39. Alidousty C, Brandes D, Heydt C, Wagener S, Wittersheim M, Schäfer SC, et al. Comparison of blood collection tubes from three different manufacturers for the collection of cell-free DNA for liquid biopsy mutation testing. J Mol Diagn. 2017;19(5):801-4. This is a comparison of the performance of different blood collection tubes, in the scope of cfDNA analysis.

40. Groelz D, Krenz T, Huebel R, Cant N, Zahedi-Nejad M, Attig N et al. Verification of liquid biopsy blood collection, ccfDNA stabilization and purification systems for liquid biopsy cancer biomarker applications. ISMRC. 2018. http://www.spidia.eu/ /media/Spidia/Files/ Verification\%20of\%20Liquid\%20Biopsy.ashx. 2018.

41. Schmidt B, Reinicke D, Reindl I, Bork I, Wollschläger B, Lambrecht $\mathrm{N}$, et al. Liquid biopsy-performance of the PAXgene ${ }^{\circledR}$ blood ccfDNA tubes for the isolation and characterization of cell-free plasma DNA from tumor patients. Clin Chim Acta. 2017;469:94-8.

42.• Risberg B, Tsui DW, Biggs H, de Almagro AR-VM, Dawson S-J, Hodgkin C, et al. Effects of collection and processing procedures on plasma circulating cell-free DNA from cancer patients. J Mol Diagn. 2018;20(6):883-92. This is a recent evaluation of the fitness-for-purpose of cfDNA for NGS analysis

43. Rothwell DG, Smith N, Morris D, Leong HS, Li Y, Hollebecque A, et al. Genetic profiling of tumours using both circulating free DNA and circulating tumour cells isolated from the same preserved whole blood sample. Mol Oncol. 2016;10(4):566-74.

44. Barrett AN, Zimmermann BG, Wang D, Holloway A, Chitty LS. Implementing prenatal diagnosis based on cell-free fetal DNA: accurate identification of factors affecting fetal DNA yield. PLoS One. 2011;6(10):e25202.
45. Norton S, Lechner J, Williams T, Fernando M. A stabilizing reagent prevents cell-free DNA contamination by cellular DNA in plasma during blood sample storage and shipping as determined by digital PCR. Clin Biochem. 2013;46(15):1561-5.

46. Board RE, Williams VS, Knight L, Shaw J, Greystoke A, Ranson M, et al. Isolation and extraction of circulating tumor DNA from patients with small cell lung cancer. Ann N Y Acad Sci. 2008;1137(1):98-107.

47. Jung M, Klotzek S, Lewandowski M, Fleischhacker M, Jung K. Changes in concentration of DNA in serum and plasma during storage of blood samples. Clin Chem. 2003;49(6):1028-9.

48. Page K, Guttery DS, Zahra N, Primrose L, Elshaw SR, Pringle JH, et al. Influence of plasma processing on recovery and analysis of circulating nucleic acids. PLoS One. 2013;8(10):e77963.

49. Xue X, Teare MD, Holen I, Zhu YM, Woll PJ. Optimizing the yield and utility of circulating cell-free DNA from plasma and serum. Clin Chim Acta. 2009;404(2):100-4.

50. Nikolaev S, Lemmens L, Koessler T, Blouin J-L, Nouspikel T. Circulating tumoral DNA: preanalytical validation and quality control in a diagnostic laboratory. Anal Biochem. 2018;542:34-9. This is a stability study for cfDNA

51. Hufnagl C, Stöcher M, Moik M, Geisberger R, Greil R. A modified phenol-chloroform extraction method for isolating circulating cell free DNA of tumor patients. J Nucleic Acids Investig. 2013;4(1):1.

52. Mauger F, Dulary C, Daviaud C, Deleuze J-F, Tost J. Comprehensive evaluation of methods to isolate, quantify, and characterize circulating cell-free DNA from small volumes of plasma. Anal Bioanal Chem. 2015;407(22):6873-8.

53.• Diefenbach RJ, Lee JH, Kefford RF, Rizos H. Evaluation of commercial kits for purification of circulating free DNA. Cancer genetics. 2018;228:21-7. This is a comparison of different cfDNA extraction methods.

54. Holmes EE, Jung M, Meller S, Leisse A, Sailer V, Zech J, et al. Performance evaluation of kits for bisulfite-conversion of DNA from tissues, cell lines, FFPE tissues, aspirates, lavages, effusions, plasma, serum, and urine. PLoS One. 2014;9(4):e93933.

55. Keeley B, Stark A, Pisanic TR II, Kwak R, Zhang Y, Wrangle J, et al. Extraction and processing of circulating DNA from large sample volumes using methylation on beads for the detection of rare epigenetic events. Clin Chim Acta. 2013;425:169-75.

56. Sozzi G, Roz L, Conte D, Mariani L, Andriani F, Verderio P, et al. Effects of prolonged storage of whole plasma or isolated plasma DNA on the results of circulating DNA quantification assays. J Natl Cancer Inst. 2005;97(24):1848-50.

57. El Messaoudi S, Rolet F, Mouliere F, Thierry AR. Circulating cell free DNA: preanalytical considerations. Clin Chim Acta. 2013;424:222-30.

58. CEN/TS 16835-3 Venous whole blood - part 3: isolated circulatining cell free DNA from plasma. 2015.

59. Amit H, Wei S, Armisen-Garrido J, Edgeworth B, Woodward R, Sninsky JJ, et al. Using cell free DNA reference standards to evaluate the analytical performance of circulating tumor DNA testing and solid organ transplant health surveillance. BioTechniques. 2015;59(4):248-50.

60.• Devonshire AS, Whale AS, Gutteridge A, Jones G, Cowen S, Foy CA, et al. Towards standardisation of cell-free DNA measurement in plasma: controls for extraction efficiency, fragment size bias and quantification. Anal Bioanal Chem. 2014;406(26):6499-512. This is an important article for a metrological approach to cfDNA.

61. Pinzani P, Salvianti F, Zaccara S, Massi D, De Giorgi V, Pazzagli M, et al. Circulating cell-free DNA in plasma of melanoma patients: qualitative and quantitative considerations. Clin Chim Acta. 2011;412(23-24):2141-5.

Publisher's Note Springer Nature remains neutral with regard to jurisdictional claims in published maps and institutional affiliations. 